\title{
Facile fabrication of functional bra cup by an automated dispensing system
}

\author{
DOI: 10.35530/IT.070.05.1583
}

YING ZHANG

TAO LI

CHENG-HAI YU

FENG-YUAN ZOU

\section{ABSTRACT - REZUMAT}

\section{Facile fabrication of functional bra cup by an automated dispensing system}

The goal of the study is to develop a novel method to manufacture the functional bras. The high precision three-dimensional (3D) scanner was employed to get the point cloud data. A fixed mount was invented to keep the bra cup stable and decrease measuring error. A bottom holder was prepared by the $3 D$ printer to place the bra cup during the injection process. Furthermore, the injection points coordinate values and the injection volumes can be determined based on the 3D image of the bra cup and the thickness of those positions. At last, the three-axis automatic robot which was coupled with a precision liquid dispenser is used to inject the microcapsules solution into the bra cup for the preparation of functional intimate apparel. The proposed method was verified to be feasible and effective through a practical example.

Keywords: functional bras, 3D scanner, data acquisition, 3D printer, automated dispensing systems, microcapsules solution

\section{Realizarea cupei funcţionale a sutienului cu un sistem automat de distribuire}

Obiectivul studiului a fost de a dezvolta o metodă nouă pentru fabricarea sutienelor funcționale. Scanerul tridimensional (3D) de înaltă precizie a fost utilizat pentru a obține datele antropometrice. A fost dezvoltat un sistem de montare fix pentru a menține cupa sutienului stabilă și pentru a reduce eroarea de măsurare. Pentru imprimanta $3 D$ a fost realizat un suport, pentru a așeza cupa sutienului în timpul procesului de injecție. Mai mult, valorile coordonatelor punctelor de injecție și volumele de injecție au putut fi determinate pe baza imaginii 3D a cupei sutienului și a grosimii respectivelor poziții. În cele din urmă, robotul automat cu trei axe, care a fost cuplat la un distribuitor precis de lichid, a fost utilizat pentru a injecta soluția de microcapsule în cupa sutienului pentru realizarea produselor de lenjerie funcționale. Metoda propusă a fost verificată ca fiind fezabilă și eficientă printr-un exemplu practic.

Cuvinte-cheie: sutiene funcționale, scaner $3 D$, achiziție de date, imprimantă $3 D$, sisteme de distribuire automată, soluție de microcapsule

\section{INTRODUCTION}

Women's satisfactions with intimate apparel, especially bras, have developed from a necessity into a multi-functional item [1-2]. New technologies have been introduced to develop innovative preparation methods to meet consumer demand for the pursuit of beauty and function [3]. However, the growth of functional bra in the commercial market lags behind the research. This may due to the poor durable functionality finished by traditional process [4]. A smart finishing process should be exploited to make full use of the special three-dimensional shape of bra. With the development of high precision three-dimensional (3D) scanning technique, it will be possible to acquire point cloud data of bra cup. Irregular triangle patches obtained from those points can generate completed bra cup data which is reliable and high accurate [56]. Meanwhile, automated dispensing system provides a direct way of dispensing finishing liquids on/into the fabrics [7]. In this study, the most common material of bra, polyurethane (PU) foam was used given its soft and flexible characteristics [8-9]. Moreover, $\mathrm{PU}$ is available in a wide range of softness and thickness, which not only provides unlimited shape designs, but also has sufficient interspace for loading the functional materials and avoiding the washing influence on the durability [10-11]. Microcapsules finishing agent is used since it is an effective method to protect functional material and control the release rate of various agents [12-13]. Therefore, combining the 3D scanning technique and automated dispensing systems can inject the different kinds of functional microcapsules solution into the bras according to the calculated position and volume to realize the durable functionality.

In this work, the microcapsules solution was injected into the PU bra cup precisely by an automated dispensing machine. First of all, the geometrical data of bra cup was acquired by the three-dimensional scanning technique. Then, the holder of the bra was made by the 3D printer. Also, injection information of the sample was determined by an adaptive program and written into three-axis automatic robot coupled with a precision dispenser. Finally, the manipulator would bring the needle to the pre-set injection position and finish the injection process. The results demonstrated 
that this novel method is effective to realize the manufacturing of the functional bra cups.

\section{EXPERIMENTAL SECTION}

\section{Materials}

Flexible polyurethane (PU) bra cups with a thickness of ca. $30 \mathrm{~mm}$ were kindly gifted from Shan Wai Shan Garment Co., Ltd., China. The size of this bra cup is $75 \mathrm{~B}$ which regarded as the typically standard in the Chinese women's lingerie market. The microcapsule solution was purchased from Herst International Group, China. The low temperature adhesive was obtained from Transfar Co., Ltd., China. The thickening agent was purchased from Rui Guang Industrial Co., Ltd., China.

\section{Data acquisition of the bra cup}

Accurate data acquisition is the basis of determining the injection location. Since the bra cup is a soft and irregular object, it is not very accessible to get its geometric information by contact measurement method [14]. Therefore, a high-precision 3D scanner (EaScan-D, Xian Lin Co., Ltd., China) with a precision of $0.05 \mathrm{~mm}$ was employed in our approach. The optical blue light 3D digitization system can capture the images quickly and combine them automatically based on the mark points. Since PU foam cups can easily deform, we used an apparatus attached with fixtures to ensure that the bra cup sample was positioned in a stable manner during the scanning process. The material of this fixed mount is PMMA which allows light to pass through. If the mark points are adhered on the sample, it will prevent scanning complete bra cups or decrease accuracy. Therefore, the mark points were adhered on the bottom of the fixed mount, which is shown in figure 1. Furthermore, the fixed mount is adjustable to accommodate bra cups with different styles or different sizes. It is remarkable that the bra cup was clamped by the fixed mount. Then, the bra cup was arranged in its nature state and the deformation would not happen. Nonetheless, the bra cup was scanned for several times to ensure precise 3D data. The reverse engineering software Geomagic was employed for merging and curvature smoothing. Data file was exported as a STL file for the subsequent processes carried out.

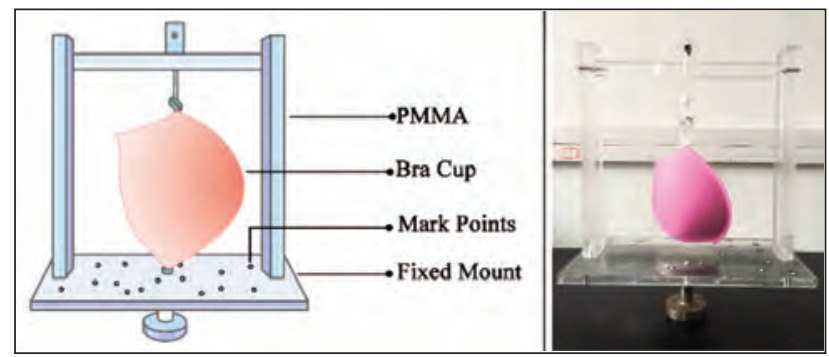

Fig. 1. The apparatus of bra cup fixed mount for scan measurement

\section{Determination of the bra cup apex}

In this approach, the bra cup should be horizontally placed onto the $X Y$ plane during the injecting process.
The position of bra cup peak was defined as the lowest point of contact surface. To obtain the apex of the bra cup on the outer surface, a base plane was built based on the theory of three points determining a plane. These three points are the left endpoint, the midpoint and the right endpoint of the bowl line bundle of the bra cup. The point with the biggest projection distance between the outer surface and the bottom horizontal plane was regarded as the apex of bra cup (see figure 2).

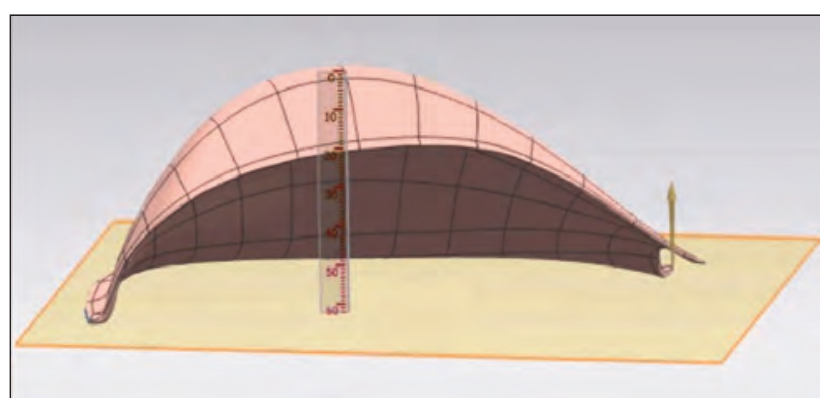

Fig. 2. Determination of the position of bra cup peak

\section{The fabrication of the bra cup holder}

As stated previously, the bra cup is irregular and flexible. Therefore, it is necessary to fabricate a holder to keep the bra cup stable during the injecting process. Firstly, the coordinate origin should be determined according to the minimum bounding box [15]. Given the bra cup in three dimensional spaces, the maximum values in $X Y, X Z, Y Z$ planes all can be obtained. The schematic diagram of finding out the minimum bounding box of the bra cup is displayed in the figure 3 , and the pseudo code is given as follow:

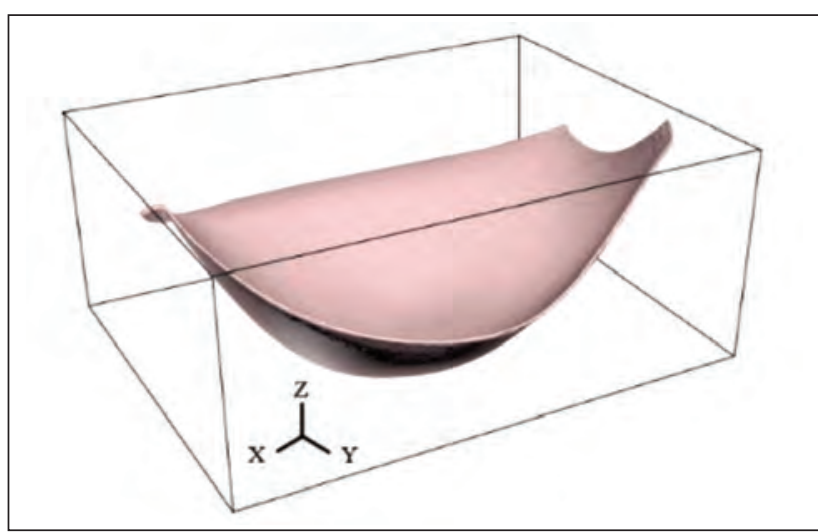

Fig. 3. Finding out the minimum bounding box of the bra cup

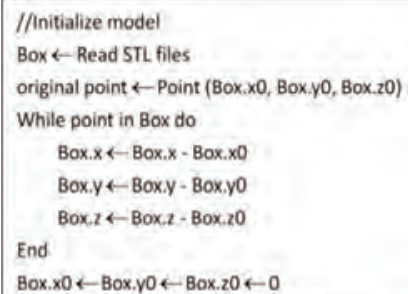

the sample step of injection points (box.x0, box.y0, box.xn, box.yn) is border of the box $\leftarrow s t^{*}$ 
The reset bra cup file was obtained and exported as a new STL file. The upper surface of the hold should be matched well to the bottom surface of the bra cup. The method of making the bra cup holder can be narrated below:

Step 1 The new bra cup file was imported in the reverse engineering software Geomagic. All data of the bra cup inner surface were deleted.

Step 2 The outer surface margin of the bra cup was smoothed. In terms of the outer surface margin, the projection was built on the XY plane.

Step 3 In order to display the coordinate origin, the bounding box of the bra cup, the four boundaries (i.e., top, bottom, left, and right ones) were marked and these edges were thickened by $10 \mathrm{~mm}$ on the $Z$ axis. The holder model of the bra cup is shown in figure 4.

Step 4 The new holder model was saved as a STL file which could be made directly by the $3 D$ printer using the PLA as the material.

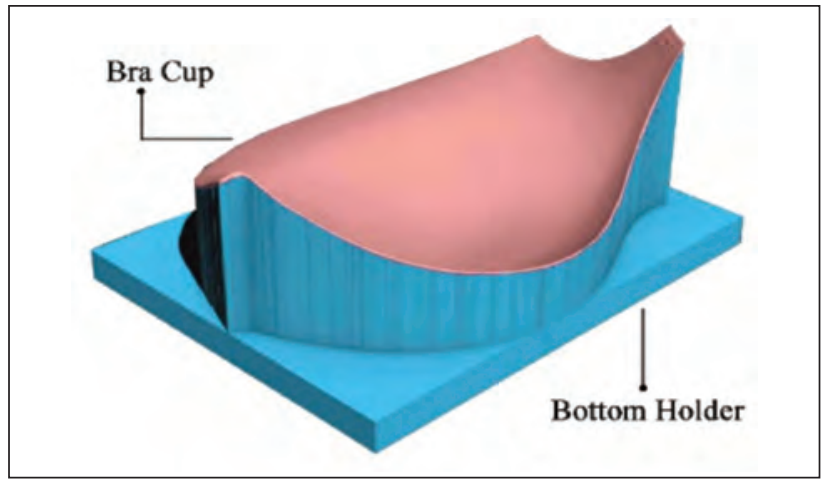

Fig. 4. The holder model of the bra cup

\section{Microcapsules solution preparation}

The microcapsules solution was consisted of $10 \mathrm{wt} \%$ PU microcapsules, 15 wt $\%$ low temperature adhesive, $1 \mathrm{wt} \%$ thickener, and $74 \mathrm{wt} \%$ deionized water. The solution was stirred at $60^{\circ} \mathrm{C}$ for 20 minutes to ensure the microcapsules solution adequate homogeneous.

\section{RESULTS AND DISCUSSION}

The automated dispensing is an efficient and effective way to deliver the solution to the designated location [16]. Especially, a home brew software was programmed, which can determine injection positions and volumes intelligently according to thickness of the points. In this software step distance and injection point number are two input parameters which could codetermine the injection positions. When the step distance was confirmed, the number of the points within $X Y$ plane was also determined. Those points were ranked in descending order based on the height difference in the Z-axis. The high ranked points were selected as the injection position and the number of those points was determined based on number preset. Furthermore, the injection dose of each point could be calculated by our software according to the Equation (1).

$$
V_{e}=H_{e} \times V_{t} / \sum_{i=1}^{n} H_{e}
$$

where $V_{e}$ represents the injection dose of each point, $V_{t}$ - the total amount of the finishing liquid, $H_{e}$ - the height difference of each injection position, and $n-$ the number of the injection points.

The injection depth is set as $1 / m$ of the thickness difference between upper surface and bottom surface, and the $m$ can be any number greater than 1. In this example, the injection depth was set as the half of thickness difference (i.e., $m=2$ ). The step distance, number of injection points, and total volume of the injection were set as $20 \mathrm{~mm}, 10$ and $5 \mathrm{~mL}$, respectively. The injection position detailed information is shown in the table 1, and the simplified pseudo code is given as follow.

Table 1

\begin{tabular}{|c|c|c|c|c|}
\hline \multicolumn{5}{|c|}{ DETAILED INFORMATION OF INJECTION POSITIONS } \\
\hline No. & Position X & Position Y & Position Z & $\begin{array}{c}\text { Injection } \\
\text { volume } \\
(\mathbf{m L})\end{array}$ \\
\hline 1 & 80.00 & 60.00 & 17.82 & 0.59 \\
\hline 2 & 60.00 & 60.00 & 17.19 & 0.57 \\
\hline 3 & 80.00 & 80.00 & 24.23 & 0.57 \\
\hline 4 & 60.00 & 80.00 & 24.49 & 0.56 \\
\hline 5 & 100.00 & 60.00 & 22.53 & 0.52 \\
\hline 6 & 100.00 & 80.00 & 26.94 & 0.49 \\
\hline 7 & 40.00 & 60.00 & 22.38 & 0.46 \\
\hline 8 & 40.00 & 80.00 & 29.11 & 0.42 \\
\hline 9 & 80.00 & 40.00 & 12.78 & 0.42 \\
\hline 10 & 60.00 & 40.00 & 12.27 & 0.40 \\
\hline
\end{tabular}

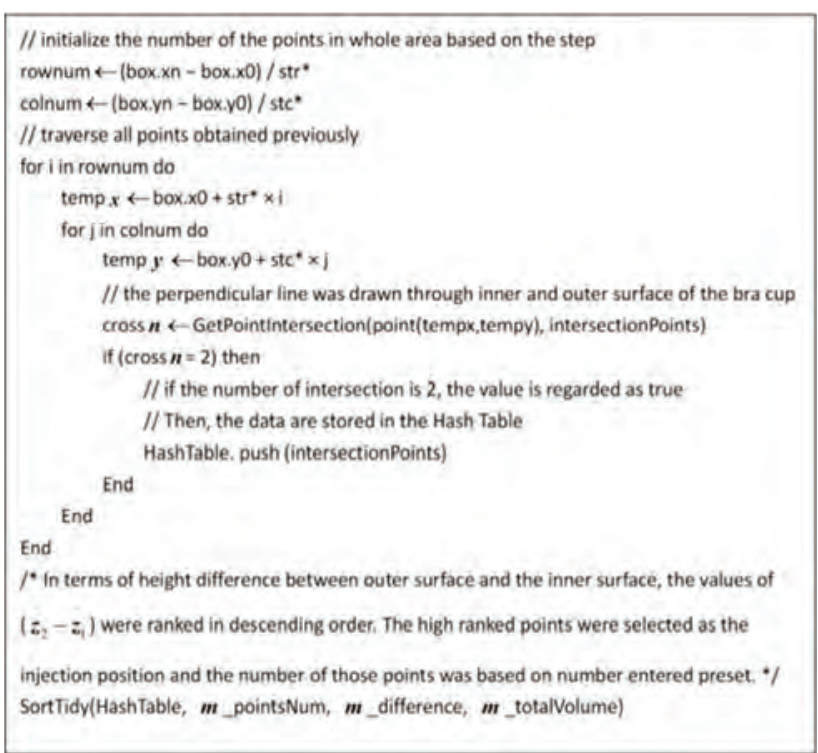

A desktop three-axis automatic robot system with precision liquid dispenser (TS-300B, Ten Sun Industrial Equipment Co., Ltd., China) was applied to deliver and inject the microcapsules solution. The 


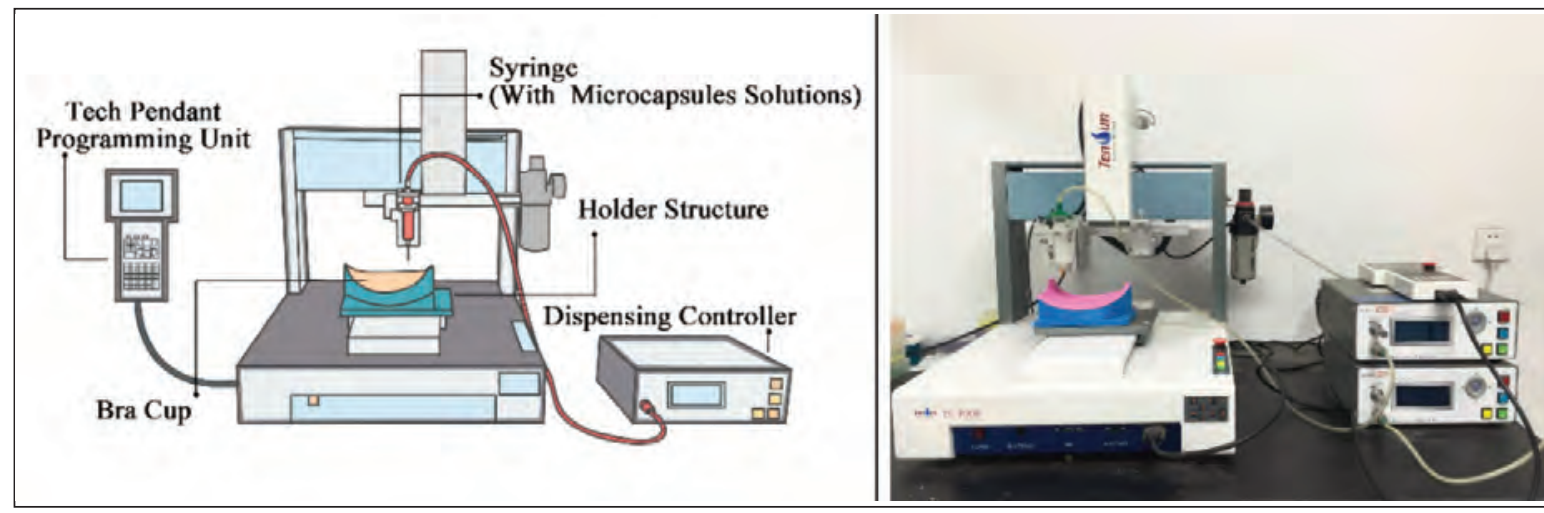

Fig. 5. Automatic dispensing system

mechanical arm attached with a needle of $0.11 \mathrm{~mm}$ in diameter and $32 \mathrm{~mm}$ in length can linear move independently in the $\mathrm{X}, \mathrm{Y}$ and $\mathrm{Z}$ directions. A schematic of such fully automated dispensing system is shown in figure 5 . The injection information was written with the teach pendant to deliver the microcapsules solutions accurately to the desired spots.

The injection volumes were controlled by the air pump pressure and dispensing time. To control injection volume accurately, the pump pressure, injection time and solution destiny were tested. The destiny of the microcapsule solution is $1.005 \mathrm{~g} / \mathrm{mL}$ measured using a force tensiometer (K100, Krüss, Germany) at $25^{\circ} \mathrm{C}$. The relation of the pump pressure and dispensing time to solution weight was measured by a precision balance (ME104E, Mettler-Toledo, Switzerland) at $25^{\circ} \mathrm{C}$. The injection rate was set as $0.05 \mathrm{~mL} / \mathrm{s}$ in the condition of pump pressure of $48 \mathrm{kPa}$. The drying treatment step was done at $80^{\circ} \mathrm{C}$ for 50 minutes (to evaporate the water) and $120^{\circ} \mathrm{C}$ for 10 minutes (to ensure adequate adhesive cross linking).

\section{CONCLUSIONS}

In this paper, a new method of automated dispensing functional microcapsule solution for bra cup is presented. Complete and accurate 3D data of bra cup can be obtained with the fixing of the fixed mount. The bottom holder ensures that the bra cup keep stable during the injection process. A parameterization program makes it possible to determine the injection location and dose smartly based on the bra cup thickness information. Furthermore, with this novel technique, the functional liquid can be dispensed accurately to the surface or interior of the irregularly shaped three-dimensional fabrics which are not limited to the bra cup.

\section{ACKNOWLEDGEMENTS}

This study is financially supported by the Zhejiang Provincial Collaborative Innovation Center of Garment Personalized Customization.

\section{REFERENCES}

[1] Beti, R.C., Slavica, B., Drago, K., Tencel with a microbial barrier for medical bras, In: Journal of Fiber Bioengineering and Informatics, 2015, 8, 4, 635-643

[2] Yick, K.L., Wu, L., Yip, J., Ng, P., Yu, W., An evaluation of the three-dimensional geometric shape of moulded bra cups, In: Fibers and Polymers, 2011, 12, 4, 556-563

[3] Kin, E.A., Yoo, S.J., Kim, J.J., Development of a human-clothing-environment simulator for dynamic heat and moisture transfer properties of fabrics, In: Fibers and Polymers, 2003, 4, 4, 215-221

[4] Li, L., Song, L., Hua, T., Au, W.M., Wong, K.S., Characteristics of weaving parameters in microcapsule fabrics and their influence on loading capability, In: Textile Research Journal, 2013, 83, 2, 113-121

[5] Yick, K.L., Wu, L., Yip, J., Ng, S.P., Yu, W., Study of thermal-mechanical properties of polyurethane foam and the three-dimensional shape of molded bra cups, In: Journal of Materials Processing Technology, 2010, 210, 1, 116-121

[6] Choi, G.B., Kim, S.M., Adaptive modeling method for 3 - D printing with various polymer materials, In: Fibers and Polymers, 2016, 17, 7, 977-983

[7] Li, B., Li, D.P., Wang, J.P., Copper deposition on textiles via an automated dispensing process for flexible micro strip antennas, In: Textile Research Journal, 2014, 84, 19, 1-10

[8] Wu, L., Yick, K.L., Ng, S.P., Yip, J., Application of the box-behnken design to the optimization of process parameters in foam cup molding, In: Expert Systems with Applications, 2012, 39, 1, 8059-8065

[9] Wu, L., Yick, K.L., Ng, S.P., Yip, J., Kong, K.H., Parametric design and process parameter optimization for bra cup molding via response surface methodology, In: Expert System with Applications, 2012, 39, 9, 162-171 
[10] Yip, J., Ng, S.P., Study of three-dimensional spacer fabrics: molding properties for intimate apparel application, In: Journal of Materials Processing Technology, 2009, 209, 1, 58-62

[11] Yu, W.M., Yeyng, K.W., Harlock, S.C., Leaf, G.A.V., Predicting energy requirements for moulding flexible polyurethane foam sheets, In: Textile Research Journal, 1998, 68, 4, 289-295

[12] Tülay, G., The role of microcapsules in masking bad odors of cotton fabrics, In: Industria Textila, 2017, 68, 4, 275-282, https://doi.org/10.35530/IT.068.04.1289

[13] Li, S., Boyter, H., Qian, L., UV curing for encapsulated aroma finish on cotton, In: The Textile Institute, 2005, 96, 6, 407-411

[14] Yick, K.L., Ng, S.P., Zhou, X.J., Yu, W., Chan, D., Wire frame representation of 3D moulded bra cup and its application to example-based design, In: Fibers and Polymers, 2008, 9, 5, 653-658

[15] Chan, C.K., Tan, S.T., Determination of the minimum bounding box of an arbitrary solid: an iterative approach, In: Computer Structures, 2001, 79, 15, 1433-1449

[16] Peddi, A., Zhen, Y.F., Cherezov, V., Caffrey, M., Efficient and effective path for automated dispensing of bioprecipitant solutions, In: Proceedings of the 2005 IEEE International Conference on Automation Science and Engineering, 2005, 61-66

Authors:

YING ZHANG ${ }^{1,2}$, TAO LI ${ }^{1}$, FENG-YUAN ZOU1,2, CHENG-HAI YU³, LEI DU1,2

${ }^{1}$ School of Fashion Design \& Engineering, Zhejiang Sci-Tech University, Hangzhou 310018, China ${ }^{2} Z$ hejiang Provincial Research Center of Clothing Engineering Technology, Hangzhou 310018, China ${ }^{3}$ School of Information Science and Technology, Zhejiang Sci-Tech University, Hangzhou 310018, China

Corresponding author:

LEI DU

e-mail: dulei@zstu.edu.cn 